\title{
Helen Salisbury: The importance of coffee
}

\author{
Helen Salisbury GP \\ Oxford
}

When I was a newly qualified GP in search of a practice that would feel like home, one of the questions I used to ask was, "When and where do you meet for coffee breaks?" Clearly, the coffee itself isn't important-it could be tea, water, or whatever-but creating a shared time and space is. The answer to my question was often revealing in what it told me about relationships at the practice: was this a supportive place, where doctors enjoyed each other's company, or one where they remained holed up in their rooms, occupying the same building but working alone?

A coffee break serves many purposes beyond simple bodily sustenance (although that too is important). It's a chance to pick colleagues' brains about a result you don't understand, to ask what to do next in a tricky case, or to update the team on a shared patient's progress. For trainees and students it's a good example of how colleagues can work together, being comfortable with admitting the limits of individual knowledge and asking for help. It also provides an informal space where they can ask questions, either clinical or practical.

Beyond the clinical, a coffee break is an opportunity to catch up with each other's lives, holidays, families, and interests outside work. Friendships forged over coffee and conversation are useful when disagreements arise, as they inevitably will at any organisation. It's much easier to debate when you know each other well. If you trust each other you can afford to disagree in meetings, spend time arguing, and allow the best decisions to emerge, unhampered by the fear that differences of opinion might spill into the rest of your working relationship.
Although I knew all of this in theory, for many years coffee breaks didn't happen at our surgery. Partly this was down to a lack of space (we really did convert a loo into the junior doctor's consulting room), as we were a small practice spread across two sites. Now we've grown and have more space, but I still encounter arguments and excuses: "There's just too much work ... my day's long enough already, and if I come for coffee now I'll be even later home."

Gradually, however, the culture of our practice is changing, and we're embedding the routine of coffee time. We're there to serve our patients to the best of our ability, but we also need to look after ourselves - to stop at least once in our day to draw breath, offload, and share a cup of something. Without this opportunity to value and support each other the likelihood of burnout increases, which is a threat to our own safety and that of our patients. $^{12}$

Competing interests: See www.bmj.com/about-bmj/freelance-contributors. Provenance and peer review: Commissioned; not externally peer reviewed.

1 Montgomery A, Panagopoulou E, Esmail A, Richards T, Maslach C. Burnout in healthcare: the case for organisational change. BMJ 2019;366:|4774. 10.1136/bmj.14774 31362957 Hall LH, Johnson J, Watt I, O'Connor DB. Association of GP wellbeing and burnout with patient safety in UK primary care: a cross-sectional survey. Br J Gen Pract 2019;69:e507-14. 10.3399/bjgp19X702713. 31015224

Published by the BMJ Publishing Group Limited. For permission to use (where not already granted under a licence) please go to http://group.bmj.com/group/rights-licensing/ permissions 